PROCEEDINGS OF THE

AMERICAN MATHEMATICAL SOCIETY

Volume 138, Number 3, March 2010, Page 1159

S 0002-9939(09)10191-0

Article electronically published on October 30, 2009

\title{
CORRIGENDUM TO \\ "A GENERALIZATION OF A THEOREM \\ OF RANKIN AND SWINNERTON-DYER ON ZEROS OF MODULAR FORMS"
}

JAYCE R. GETZ

(Communicated by Ken Ono)

J. Rouse pointed out to the author that there is a mistake in the proof of Theorem 2, the main result of the paper "A generalization of a theorem of Rankin and Swinnerton-Dyer on zeros of modular forms", Proc. Amer. Math. Soc. 132 (2004), 2221-2231. More specifically, the claim in equation (3.8) is incorrect. The diagonal entries of the matrix will be strictly larger than the entries above the diagonal as $i$ approaches infinity. The error cannot be corrected in any obvious manner. However, Theorem 2 is still true as stated; it is a special case of [DJ, Theorem 1]. W. Duke and P. Jenkin's proof is independent of our flawed argument.

\section{REFERENCES}

[DJ] W. Duke and P. Jenkins, On the zeros and coefficients of certain weakly holomorphic modular forms, Pure and Applied Mathematics Quarterly 4 (2008), 1327-1340. MR2441704

Department of Mathematics, Princeton University, Princeton, New Jersey 085441000

E-mail address: jgetz@math.princeton.edu

Received by the editors September 2, 2009.

2000 Mathematics Subject Classification. Primary 11F11.

(C)2009 American Mathematical Society Reverts to public domain 28 years from publication 